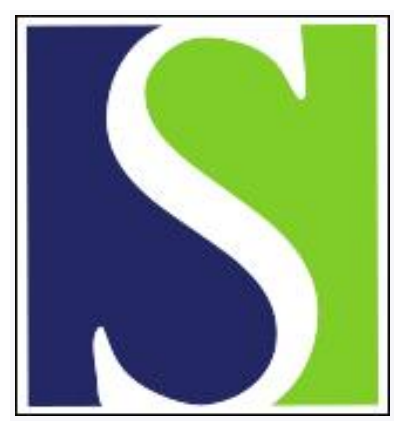

Scand J Work Environ Health 1985;11(2):101-106

https://doi.org/10.5271/sjweh.2247

Issue date: Apr 1985

Symptoms and clinical findings in patients with silicosis.

by Koskinen $\mathrm{H}$

This article in PubMed: www.ncbi.nlm.nih.gov/pubmed/4001897

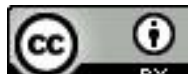

This work is licensed under a Creative Commons Attribution 4.0 International License 


\title{
Symptoms and clinical findings in patients with silicosis
}

\author{
by Heikki Koskinen, MD ${ }^{1}$
}

\begin{abstract}
KOSKINEN H. Symptoms and clinical findings in patients with silicosis. Scand $J$ Work Environ Health 11 (1985) 101-106. Respiratory symptoms, radiographic findings, and lung function were analyzed in 144 Finnish patients with silicosis. The prevalence of persistent phlegm production in these patients was $46 \%$ and that of dyspnea $87 \%$. Impairment of the vital capacity (VC) and the diffusion capacity $\left(\mathrm{DL}_{\mathrm{CO}}\right)(<80 \%$ of predicted values) were found in 46 and $47 \%$ of the patients with simple silicosis, respectively. The mean $D_{C O}$ was lower in patients with advanced simple silicosis (category 3 ) than in those with slight simple silicosis (categories 1 and 2). In category 3 the $\mathrm{DL}_{\mathrm{co}}$ was impaired in 9 out of 12 patients, the impairment being below $65 \%$ of the predicted values in six of the nine. All patients with large opacities showed impairment in their lung function tests. Twenty-eight of the silicosis patients had referents matched for exposure to silica dust, age, and gender. The referents had no radiographic signs of silicosis. The patients experienced dyspnea more often than their referents, whereas no difference was found in the prevalence of persistent phlegm production. The mean values of VC, forced expiratory volume in $1 \mathrm{~s}\left(\mathrm{FEV}_{1.0}\right)$, and $\mathrm{DL}_{\mathrm{CO}}$ were lower in the patients than in the referents. The results indicate a high prevalence of dyspnea, restrictive impairment of lung function, and impaired diffusion capacity in the patients with simple or complicated (ie, large radiographic opacities) silicosis. The $\mathrm{DL}_{\text {co }}$ proved to be a rather sensitive lung function parameter for advanced simple silicosis.
\end{abstract}

Key terms: lung function, silica exposure.

Silicosis may occur in occupations where siliceous materials are encountered. Patients with simple silicosis - that is, with multiple, rounded opacities of various profusion as seen in a chest radiograph have no respiratory symptoms (12). Symptoms indicative of chronic bronchitis are equally common in silicotics and in subjects similarly exposed but without silicosis $(3,12)$. Dyspnea on effort is the most common feature of silicosis $(4,14)$; this symptom is, however, usually associated with complicated (eg, cases with large radiographic opacities) rather than with simple silicosis (14), which does not usually produce significant impairment in lung function $(4,8$, $12,14)$. The focal fibrosis may be associated with a slight decrease in vital capacity or total lung capacity (12), or it may produce spirometric evidence of small airways disease or evidence of impaired gas mixing (4).

The principal symptom of patients with complicated silicosis - that is, eg, with large radiographic opacities - is shortness of breath on exercise $(4,12$, 14). The functional pattern in such cases may be one of obstruction, mixed obstruction and restriction, or pure restriction (4). The diffusion capacity at this stage is reduced (12).

The objective of the present study was to assess the interrelationships between respiratory symptoms, radiographic findings, and lung function variables in a series of Finnish silicosis patients. The patients were compared with referents matched for silica dust

\footnotetext{
1 Department of Occupational Medicine, Institute of Occupational Health, Helsinki, Finland.
}

Reprint requests to: Dr $\mathrm{H}$ Koskinen, Institute of Occupational Health, Haartmaninkatu 1, SF-00290 Helsinki, Finland. exposure, age, and gender, but with no radiographic signs of silicosis.

\section{Subjects and methods}

\section{Subjects}

A total of 306 cases of silicosis were reported to the Finnish Occupational Disease Register in 19651977. The patient group for this clinical reexamination of persons with silicosis was obtained from these reported cases. The study was performed in 1979 at the Institute of Occupational Health in Helsinki.

The diagnostic criteria for silicosis included a verified history of occupational exposure to silica dust, or mixed dust including silica, and a radiographic finding consistent with silicosis. To avoid false positive cases of silicosis, I reevaluated the occupational history and clinical data from the patient records of the $\mathbf{3 0 6}$ reported cases of silicosis and also reviewed the chest radiographs together with two radiologists. A total of 243 of the persons reported to have silicosis were alive, and 63 had died before 1979. All 243 living silicosis patients had a verified history of occupational silica dust exposure. Twenty-five of them were excluded from the reexamination because the radiographic or clinical findings were inconsistent with silicosis. Twenty patients could not attend the reexamination because of poor health, mainly due to old age. Forty could not be traced, and 14 refused the reexamination. Thus 144 patients (138 men and 6 women) with silicosis were available for reexamination, and they formed the patient group of my study. The data on their gender, age, occupational history, 
and duration of exposure to silica dust are presented in table 1.

Twenty-three $(16 \%)$ of the 144 silicosis patients had a history of pulmonary tuberculosis, which was active in two patients at the time of the reexamination.

In order that the effect of silica dust on symptoms and clinical findings could be studied in nondiseased workers, an attempt was made to find a referent for as many of the silicosis patients as possible. Matching one referent to one patient for gender, age $( \pm 5$ years), and duration of exposure ( \pm 5 years) to silica dust in the same workplace and similar working tasks produced 28 male pairs. One of the referents was, however, nine years younger than his matched patient. The data on age, occupational history, and duration of silica dust exposure, as well as the data on the radiographic findings, of these 28 patients and referents are given in table 2 . Five of these patients, in contrast to 25 referents, were currently exposed to silica dust when the examination was performed, whereas the other patients had been exposed 1 to 14 (mean 5) years earlier.

The smoking habits of the 28 patients and their referents, as well as of the patients in various radiographic profusion categories, were similar. Of the 144 patients, 25 were nonsmokers, 71 exsmokers, and 48 current smokers.

\section{Methods}

The occupational and medical histories of the patients with silicosis and the referents were obtained in interviews carried out by myself. A questionnaire of the Medical Research Council (7) was used in the assessment of the respiratory symptoms. A smoker was defined as a subject who still smoked or who had given it up less than three months prior to the interview, an exsmoker was someone who had given up smoking more than three months before, and a nonsmoker was a person who had never smoked regularly. Persistent production of phlegm was defined as the production of phlegm for at least three months

Table 1. Data on the sex, age at the time of examination, occupational history, and silica dust exposure of the 144 silicosis patients.

\begin{tabular}{|c|c|c|c|c|c|c|c|}
\hline \multirow{2}{*}{ Occupation } & \multirow{2}{*}{$\begin{array}{l}\text { Sex } \\
(\mathrm{M} / \mathrm{F})\end{array}$} & \multicolumn{3}{|c|}{ Age (years) } & \multicolumn{3}{|c|}{ Years exposed } \\
\hline & & Mean & SD & Range & Mean & SD & Range \\
\hline Miners $(N=18)$ & $17 / 1$ & 59.3 & 7.0 & $47-70$ & 22.2 & 7.0 & $8-34$ \\
\hline Stone workers $(\mathrm{N}=22)$ & $22 / 0$ & 63.2 & 7.0 & $47-72$ & 30.5 & 8.2 & $6-44$ \\
\hline Steel foundry workers $(N=23)$ & $23 / 0$ & 57.2 & 8.6 & $40-70$ & 23.7 & 8.3 & $11-43$ \\
\hline Iron foundry workers $(\mathrm{N}=36)$ & $35 / 1$ & 59.9 & 5.8 & $45-70$ & 27.1 & 8.6 & $6-45$ \\
\hline Ceramics industry workers $(N=10)$ & $6 / 4$ & 59.9 & 10.2 & $36-73$ & 29.8 & 9.4 & $15-43$ \\
\hline $\begin{array}{l}\text { Tunneling and construction } \\
\text { workers }(\mathrm{N}=13)\end{array}$ & $13 / 0$ & 56.2 & 7.1 & $47-73$ & 21.1 & 6.6 & $11-33$ \\
\hline Glass factory workers $(N=5)$ & $5 / 0$ & 54.1 & 7.6 & $46-62$ & 19.8 & 10.6 & $4-30$ \\
\hline Miscellaneous $(\mathrm{N}=17)$ & $17 / 0$ & 52.3 & 8.8 & $33-68$ & 12.8 & 6.5 & $4-29$ \\
\hline Total $(N=144)$ & $138 / 6$ & 58.3 & 8.1 & $33-73$ & 24.2 & 9.5 & $4-45$ \\
\hline
\end{tabular}

Table 2. Data on the age, occupational history, silica dust exposure, and radiographic findings of the 28 male silicosis patients with referents matched for gender, age, and silica dust exposure and on their matched referents.

\begin{tabular}{|c|c|c|c|c|c|c|c|c|}
\hline & \multicolumn{4}{|c|}{ Silicosis patients $(\mathrm{N}=\mathbf{2 8})$} & \multicolumn{4}{|c|}{ Referents (N = 28) } \\
\hline & $\mathbf{N}$ & Mean & SD & Range & $N$ & Mean & SD & Range \\
\hline Age (years) & . & 56.2 & 7.6 & $40-69$ & . & 53.9 & 7.6 & $31-74$ \\
\hline \multicolumn{9}{|l|}{ Occupation } \\
\hline $\begin{array}{l}\text { Miners } \\
\text { Stone workers } \\
\text { Steel foundry workers } \\
\text { Iron foundry workers } \\
\text { Ceramics industry workers } \\
\text { Miscellaneous }\end{array}$ & $\begin{array}{l}9 \\
1 \\
8 \\
5 \\
3 \\
2\end{array}$ & $\begin{array}{l}\dot{s} \\
\dot{.} \\
\dot{.}\end{array}$ & : & $\begin{array}{l}\dot{.} \\
\dot{.} \\
\dot{.}\end{array}$ & $\begin{array}{l}9 \\
1 \\
8 \\
5 \\
3 \\
2\end{array}$ & $\begin{array}{l}\dot{.} \\
\dot{.} \\
\dot{.}\end{array}$ & $\dot{i}$ & $\begin{array}{l}\dot{.} \\
\dot{.} \\
\dot{.}\end{array}$ \\
\hline Years exposed & . & 24.8 & 7.9 & $10-40$ & . & 27.4 & 7.8 & $10-41$ \\
\hline \multicolumn{9}{|c|}{ Radiographic profusion categorya } \\
\hline $\begin{array}{l}0 \\
1 \\
2 \\
3\end{array}$ & $\begin{array}{r}- \\
8 \\
16 \\
4\end{array}$ & $\dot{.}$ & . & . & $\begin{array}{l}28 \\
- \\
-\end{array}$ & $\dot{.}$ & $\begin{array}{l}. \\
\dot{.}\end{array}$ & . \\
\hline
\end{tabular}


each year for two years or more. The definitions for various degrees of breathlessness are given in table 3 .

The radiographic examination of the patients and referents included two full-size posteroanterior and one lateral radiograph. The radiographic technique has been described in detail elsewhere (15). The chest radiographs of the patients and referents were classified independently by two physicians (one radiologist and myself) with experience in reading chest radiographs of pneumoconiosis patients using the 1980 classification of radiographs of pneumoconioses published by the International Labour Organisation (ILO) (2). The radiographs were classified without access to the identification data on the films. If the two classifiers did not agree in their independent grading assessment, the films were reviewed jointly, and a category was agreed upon.

Large opacities, as defined by the ILO classification (2), were recorded for only nine patients with silicosis, the number of patients with simple nodular silicosis therefore being 135 . Six of the nine had a profusion of small opacities of category 3, and three a profusion of category 2 .

A Bernstein type of spirometer (Kifa, Sweden) was used to measure the vital capacity (VC), the forced vital capacity (FVC), and the forced expiratory volume in $1 \mathrm{~s}\left(\mathrm{FEV}_{1.0}\right) . \mathrm{FEV}_{0}$ (the percentage ratio of $\mathrm{FEV}_{1.0}$ to $\mathrm{FVC}$ ) was calculated as $\mathrm{FEV}_{1.0} / \mathrm{FVC} \times$ 100. The carbon monoxide diffusion capacity $\left(\mathrm{DL}_{\mathrm{CO}}\right)$ was measured with a transfer apparatus (Morgan, England). The VC, $\mathrm{FEV}_{1.0}$, and $\mathrm{DL}_{\mathrm{CO}}$ are given as a percentage of the predicted values. The reference values were obtained from Berglund et al (1) and Salorinne (11). The ventilatory impairment was considered to be obstructive if the FEV $\%$ was at least 13 percentage units less than the predicted value (FEV \% $<-13 \%$ of predicted) and restrictive if the VC was less than $80 \%$ of the predicted value. Values less than $80 \%$ of the predicted $\mathrm{VC}, \mathrm{FEV}_{1.0}$, and $\mathrm{DL}_{\mathrm{CO}}$ refers to values lower than the mean minus two standard deviations and those less than $65 \%$ of predicted to values lower than the mean minus four standard deviations of the reference values.

The statistical significance of the differences in the prevalence data on the cross-sectional unpaired samples was tested with the Pearson chi-square test; in comparisons with low frequencies, Fisher's exact probability test was used. When the cases and their referents were compared, the McNemar test or the ttest for pairwise differences was used. The Student's t-test was applied to the significance testing of differences in lung function between unpaired groups.

\section{Results}

\section{Symptoms of patients with silicosis}

Sixty-six $(46 \%)$ of the 144 patients with silicosis had a persistent production of phlegm; $10(15 \%)$ of the
66 were nonsmokers. Persistent phlegm production was not associated with the radiographic profusion categories of simple silicosis or with the occurrence of large opacities.

Some degree of dyspnea was experienced by 125 $(87 \%)$ of the patients. In patients with simple silicosis a slight inclination towards a higher degree of breathlessness was observed with advancing radiographic profusion (table 3), which, however, was not significant. All nine patients with large opacities experienced dyspnea, three of grade 2, four of grade 3, and one each of grades 4 and 5 .

\section{Lung function in relation to the radiographic findings of the patients with silicosis}

Table 4 shows the mean values of the lung function tests (reliable spirometric measurements obtained for 139 patients and reliable $\mathrm{DL}_{\mathrm{CO}}$ measurements for 134 patients) in relation to the radiographic findings of the patients with silicosis. The mean value of the $\mathrm{DL}_{\mathrm{CO}}$ was lower for the patients in radiographic profusion category 3 than for those in category 2 (p $<0.01)$ or category 1 ( $p<0.01)$, whereas the patients in categories 1 and 2 did not differ at a statistically significant level. The $\mathrm{DL}_{\mathrm{CO}}$ was also lower in the patients with than in those without large opacities ( $\mathrm{p}<0.001)$. For the patients with large opacities the $\mathrm{DL}_{\mathrm{CO}}$ was 56 (SD 13) \% of the predicted value, and for the patients in category 3 the corresponding value was 65 (SD 20) \% of the predicted.

The proportion of silicosis patients with impaired lung function (VC, $\mathrm{FEV}_{1.0}$, or $\mathrm{DL}_{\mathrm{CO}}<80 \%$ or FEV $\%<-13 \%$ of the predicted values) is presented in table 5 in relation to the radiographic profusion categories. The VC and $\mathrm{DL}_{C O}$ were less than $80 \%$ of the predicted values in 46 and $47 \%$ of the patients with simple silicosis, respectively, and obstruction impairment (FEV\% $<-13 \%$ of the pre-

Table 3. Breathlessness in relation to the radiographic profusion of small opacities in the 135 patients with simple silicosis.

\begin{tabular}{|c|c|c|c|c|c|c|}
\hline \multirow{3}{*}{$\begin{array}{l}\text { Grade of breath- } \\
\text { lessness }^{a}\end{array}$} & \multicolumn{6}{|c|}{ Radiographic profusion categoryb } \\
\hline & \multicolumn{2}{|c|}{$\begin{array}{c}\text { Category } 1 \\
(N=55)\end{array}$} & \multicolumn{2}{|c|}{$\begin{array}{c}\text { Category } 2 \\
(\mathrm{~N}=68)\end{array}$} & \multicolumn{2}{|c|}{$\begin{array}{c}\text { Category } 3 \\
(N=12)\end{array}$} \\
\hline & $\mathrm{N}$ & $\%$ & $\mathbf{N}$ & $\%$ & $N$ & $\%$ \\
\hline $\begin{array}{l}1 \\
2 \text { or more } \\
3 \text { or more } \\
4 \text { or more } \\
5\end{array}$ & $\begin{array}{r}11 \\
44 \\
22 \\
4 \\
-\end{array}$ & $\begin{array}{r}20 \\
80 \\
40 \\
7 \\
0\end{array}$ & $\begin{array}{r}7 \\
61 \\
31 \\
8 \\
-\end{array}$ & $\begin{array}{r}10 \\
90 \\
46 \\
12 \\
0\end{array}$ & $\begin{array}{r}1 \\
11 \\
10 \\
4 \\
1\end{array}$ & $\begin{array}{r}8 \\
92 \\
83 \\
33 \\
8\end{array}$ \\
\hline
\end{tabular}

a Grade of breathlessness: Grade $1=$ no abnormal breathlessness, grade 2 = shortness of breath when hurrying on level ground or walking up a slight hill, grade $3=$ shortness of breath when walking with other people of the same age on level ground, grade $4=$ stopping for breath when walking at own pace on level ground, grade $5=$ shortness of breath when putting on clothes or moving out of doors.

- Category $1=1 / 0-1 / 2$, category $2=2 / 1-2 / 3$, and category $3=3 / 2-3 /+$. The categories refer to the ILO 1980 clas sification of pneumoconioses (2). 
Table 4. Mean pulmonary lung function values (\% of predicted) in relation to the radiographic findings of the patients with silicosis (reliable spirometric measurements obtained for 139 patients and reliable DL

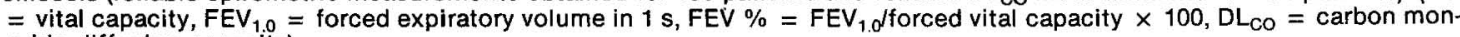
oxide diffusion capacity)

\begin{tabular}{|c|c|c|c|c|c|c|c|c|c|c|c|c|}
\hline \multirow{2}{*}{$\begin{array}{l}\text { Radiographic } \\
\text { finding }^{\mathrm{a}}\end{array}$} & \multicolumn{3}{|c|}{ VC } & \multicolumn{3}{|c|}{$\mathrm{FEV}_{1.0}$} & \multicolumn{3}{|c|}{ FEV $\%(\text { delta } \%)^{b}$} & \multicolumn{3}{|c|}{$\mathrm{DL}_{\mathrm{CO}^{\mathrm{C}}}$} \\
\hline & $N$ & Mean & SD & $\mathbf{N}$ & Mean & SD & $\mathrm{N}$ & Mean & SD & $\mathrm{N}$ & Mean & SD \\
\hline $\begin{array}{l}\text { Patients with small } \\
\text { opacities only }\end{array}$ & 130 & 82 & 16 & 130 & 88 & 23 & 130 & +6.2 & 11.4 & 125 & 82 & 21 \\
\hline $\begin{array}{l}\text { Category } 1 \\
\text { Category } 2 \\
\text { Category } 3\end{array}$ & $\begin{array}{l}52 \\
66 \\
12\end{array}$ & $\begin{array}{l}82 \\
83 \\
78\end{array}$ & $\begin{array}{l}19 \\
14 \\
14\end{array}$ & $\begin{array}{l}52 \\
66 \\
12\end{array}$ & $\begin{array}{l}89 \\
88 \\
81\end{array}$ & $\begin{array}{l}26 \\
20 \\
27\end{array}$ & $\begin{array}{l}52 \\
66 \\
12\end{array}$ & $\begin{array}{l}+7.0 \\
+6.4 \\
+5.5\end{array}$ & $\begin{array}{l}11.6 \\
11.1 \\
12.2\end{array}$ & $\begin{array}{l}50 \\
63 \\
12\end{array}$ & $\begin{array}{l}85 \\
82 \\
65\end{array}$ & $\begin{array}{l}23 \\
18 \\
20\end{array}$ \\
\hline $\begin{array}{l}\text { Patients with } \\
\text { large opacities }\end{array}$ & 9 & 77 & 14 & 9 & 74 & 25 & 9 & -0.4 & 14.5 & 9 & 56 & 13 \\
\hline
\end{tabular}

a Category $1=1 / 0-1 / 2$, category $2=2 / 1-2 / 3$, category $3=3 / 2-3 /+$. The categories, as well as the large opacities, refer to the ILO 1980 classification of pneumoconioses (2).

b Delta $\%$ indicates the positive $(+)$ or negative $(-)$ deviation from the predicted FEV \%.

c Statistical significance of differences in D $L_{\mathrm{CO}}$ (Student's t-test): category 3 vs category 1: $p<0.01$; category 3 vs category 2: $p<0.01$; patients with large opacities vs those without: $p<0.001$.

Table 5. Proportion of simple silicosis patients with impaired lung function in relation to the radiographic profusion category. $\left(\mathrm{VC}=\right.$ vital capacity, $\mathrm{FEV}_{1,0}=$ forced expiratory volume in $1 \mathrm{~s}, \mathrm{FEV} \%=\mathrm{FEV}_{1.0}$ /forced vital capacity $\times 100, \mathrm{DL}_{\mathrm{co}}=$ carbon monoxide diffusion capacity)

\begin{tabular}{|c|c|c|c|c|c|c|c|c|}
\hline \multirow{2}{*}{$\begin{array}{l}\text { Radiographic } \\
\text { finding }^{a}\end{array}$} & \multicolumn{2}{|c|}{$\begin{array}{c}\mathrm{VC}<80 \% \text { of } \\
\text { predicted }\end{array}$} & \multicolumn{2}{|c|}{$\begin{array}{c}\text { FEV }_{1.0}<80 \% \text { of } \\
\text { predicted }\end{array}$} & \multicolumn{2}{|c|}{$\begin{array}{c}\text { FEV } \%<-13 \% \text { of } \\
\text { predicted }\end{array}$} & \multicolumn{2}{|c|}{$\begin{array}{c}D L_{c o}<80 \% \text { of } \\
\text { predicted }\end{array}$} \\
\hline & Proportion ${ }^{b}$ & $\%$ & Proportion ${ }^{b}$ & $\%$ & Proportion ${ }^{b}$ & $\%$ & Proportion ${ }^{b}$ & $\%$ \\
\hline $\begin{array}{l}\text { Category } 1 \\
\text { Category } 2 \\
\text { Category } 3\end{array}$ & $\begin{array}{r}\text { 25: } 52 \\
\text { 29: } 66 \\
6: 12\end{array}$ & $\begin{array}{l}48 \\
44 \\
50\end{array}$ & $\begin{array}{r}\text { 18: } 52 \\
\text { 22: } 66 \\
6: 12\end{array}$ & $\begin{array}{l}35 \\
33 \\
50\end{array}$ & $\begin{array}{l}4: 52 \\
\text { 3: } 66 \\
\text { 2: } 12\end{array}$ & $\begin{array}{r}8 \\
5 \\
17\end{array}$ & $\begin{array}{r}\text { 22: } 50 \\
\text { 28: } 63 \\
9: 12\end{array}$ & $\begin{array}{l}44 \\
44 \\
75\end{array}$ \\
\hline Total & $60: 130$ & 46 & $46: 130$ & 35 & $9: 130$ & 7 & $59: 125$ & 47 \\
\hline
\end{tabular}

a Category $1=1 / 0-1 / 2$, category $2=2 / 1-2 / 3$, category $3=3 / 2-3 /+$. The categories refer to the ILO 1980 classification of pneumoconioses (2).

b The number of patients with impaired function in relation to all patients in the radiographic category.

Table 6. Lung function (\% of predicted) of the silicosis patients with matched referents and of the referents (reliable spirometric and $\mathrm{DL}_{\mathrm{co}}$ measurements obtained for 26 pairs). ( $\mathrm{VC}=$ vital capacity, $\mathrm{FEV}_{1.0}=$ forced expiratory volume in $1 \mathrm{~s}$, FEV $\%=\mathrm{FEV}_{1.0}$ forced vital capacity $\times 100, \mathrm{DL}_{\mathrm{co}}=$ carbon monoxide diffusion capacity)

\begin{tabular}{|c|c|c|c|c|c|c|c|}
\hline \multirow{2}{*}{ Lung function test } & \multicolumn{3}{|c|}{ Silicosis patients } & \multicolumn{3}{|c|}{ Referents } & \multirow{2}{*}{ p-Value ${ }^{a}$} \\
\hline & $\mathrm{N}$ & Mean & SD & $\mathrm{N}$ & Mean & SD & \\
\hline $\begin{array}{l}\text { VC } \\
\text { FEV }_{1.0} \\
{\text { FEV } \%(\text { delta } \%)^{b}}^{b} \\
\text { DL }_{\text {CO }}\end{array}$ & $\begin{array}{l}26 \\
26 \\
26 \\
26\end{array}$ & $\begin{array}{c}84 \\
95 \\
+11.3 \\
81\end{array}$ & $\begin{array}{l}16 \\
23 \\
10.2 \\
20\end{array}$ & $\begin{array}{l}26 \\
26 \\
26 \\
26\end{array}$ & $\begin{array}{c}93 \\
104 \\
+10.4 \\
99\end{array}$ & $\begin{array}{c}11 \\
13 \\
7.0 \\
16\end{array}$ & $\begin{array}{c}p<0.05 \\
p<0.05 \\
\text { NS } \\
p<0.001\end{array}$ \\
\hline
\end{tabular}

a The statistical comparisons were performed with the paired t-test (NS $=$ not significant).

b Delta $\%$ indicates the positive $(+)$ or negative $(-)$ deviation from the predicted FEV $\%$.

dicted) was found in $7 \%$ (table 5). Twenty-two $(37 \%)$ of the patients with a decreased $\mathrm{DL}_{\mathrm{CO}}$ had no restrictive pattern in their spirogram. In nonsmoking patients with simple silicosis the VC or $\mathrm{FEV}_{1.0}$ was less than $80 \%$ of the predicted values in 5 out of 25 patients $(20 \%)$; the same applied to the $\mathrm{DL}_{\mathrm{CO}}$ of 7 out of 24 patients $(29 \%)$. The corresponding figures for the group consisting of current smokers and exsmokers were $52 \%$ for VC, $39 \%$ for $\mathrm{FEV}_{1.0}$, and $51 \%$ for $\mathrm{DL}_{\mathrm{CO}}$.

The VC, $\mathrm{FEV}_{1.0}$, and $\mathrm{DL}_{\mathrm{CO}}$ were less than $65 \%$ of the predicted values in $15(12 \%), 14(11 \%)$, and $25(20 \%)$ of the patients with simple silicosis, respec- tively. In radiographic profusion category 3 the same degree of impairment was found for the $\mathrm{DL}_{\mathrm{CO}}$ of 6 of the 12 patients $(50 \%)$.

In patients with large opacities $(\mathrm{N}=9)$ the $\mathrm{VC}$, $\mathrm{FEV}_{1.0}$, and $\mathrm{DL}_{\mathrm{CO}}$ were less than $80 \%$ of the predicted values in seven, five, and nine patients, respectively. The VC was less than $65 \%$ of the predicted value in two patients. The $\mathrm{FEV}_{1.0}$ was also less than $65 \%$ of the predicted value in four patients, and the $\mathrm{DL}_{\mathrm{CO}}$ was lowered to a corresponding degree in seven patients. The ventilatory function was obstructive (FEV $\%<-13 \%$ of predicted) in two patients. 
Symptoms and lung function in the silicosis patients and their matched referents

The prevalence of persistent phlegm production in the 28 silicosis patients and their referents (43 vs $32 \%$ ) did not differ at a statistically significant level. The 28 patients with silicosis experienced dyspnea more of ten than the referents ( 93 vs $21 \%$, chi square $=18.2, \mathrm{p}<0.0001$ ).

The silicosis patients had statistically significantly lower mean values for VC, $\mathrm{FEV}_{1.0}$, and $\mathrm{DL}_{\mathrm{CO}}$ (reliable measurements for 26 pairs) than their similarly exposed referents (table 6). The VC, $\mathrm{FEV}_{1.0}$, and $\mathrm{DL}_{\mathrm{CO}}$ were less than $80 \%$ of the predicted values in $9(35 \%), 3(12 \%)$, and $11(42 \%)$ of the 26 patients, respectively. Such an impairment was found for VC in three $(12 \%)$, for $\mathrm{FEV}_{1.0}$ in one $(4 \%)$, and for $\mathrm{DL}_{\mathrm{CO}}$ in two $(8 \%)$ referents, all of whom were smokers or exsmokers.

\section{Discussion}

It has been suggested that simple silicosis does not usually produce significant impairment in lung function $(4,8,12,14)$. The present patients with simple silicosis showed, however, a rather high prevalence $(46 \%)$ of a restrictive pattern (VC $<80 \%$ of predicted) in their spirogram. The VC was below $65 \%$ of the predicted value in $15 \%$ of these patients. Obstructive impairment (FEV $\%<-13 \%$ of predicted) was a rare feature $(7 \%)$ in the patients with simple silicosis.

A high proportion (47 \%) of all the patients with simple silicosis had an impaired $\mathrm{DL}_{\mathrm{CO}}(<80 \%$ of predicted), in contrast to some earlier observations $(5,13)$ indicating that the $\mathrm{DL}_{\mathrm{CO}}$ is not impaired in cases of simple nodular silicosis in general. Nine of the 12 patients in category 3 had an impaired $\mathrm{DL}_{\mathrm{co}}$, the impairment being below $65 \%$ of the predicted in as many as six patients. This finding suggests that $\mathrm{DL}_{\mathrm{CO}}$ is a rather sensitive lung function parameter for patients with advanced simple silicosis (category 3). Moreover, the mean $\mathrm{DL}_{\mathrm{CO}}$ was lower in patients of category 3 than in those of categories 1 and 2 (65 vs 85 and $82 \%$ of the predicted).

The prevalences of lung function impairment among the nonsmoking patients with simple silicosis (VC $20 \%, \mathrm{FEV}_{1.0} 20 \%, \mathrm{DL}_{\mathrm{CO}} 29 \%$ ) were lower than those of patients who were smokers or exsmokers (VC $52 \%, \mathrm{FEV}_{1.0} 39 \%, \mathrm{DL}_{\mathrm{CO}} 51 \%$ ). This finding indicates that smoking modified the ventilatory function and diffusion capacity of the patients with simple silicosis. Although found in a relatively small number of nonsmoking patients with simple silicosis, the results further indicate that many nonsmoking patients with simple silicosis have an impaired lung function.

An impairment of spirometric lung function or diffusion capacity or a combination of the two was found in all the patients with large opacities. The result corroborates earlier observations and the suggestions of reviewers $(4,5,8,12,13,14)$.

As noted earlier $(9,10)$, the prevalence of dyspnea on exertion was high among the silicosis patients. Unexpectedly, dyspnea was not associated with the profusion of small opacities, although a trend towards a higher degree of dyspnea was found with more advanced cases of simple silicosis. However, all nine patients with large opacities experienced dyspnea, even grades 4 and 5 (one case each).

The mean values of $\mathrm{VC}, \mathrm{FEV}_{1.0}$, and $\mathrm{DL}_{\mathrm{CO}}$ were lower in the silicosis patients than in their exposurematched referents with similar smoking habits. This finding suggests that silicosis rather than silica dust exposure per se affects pulmonary function. In this respect the results contradict those of Irwig \& Rocks (3), who did not find any difference in FVC and FEV $_{1.0}$ among silicotic gold miners and their referents matched for age, dust exposure, and smoking. Moreover the present patients with silicosis experienced dyspnea more often than their referents. The prevalence of persistent phlegm production was not higher in the patients than in the referents, however, and therefore the phlegm production may not have been caused by the silicotic process, a possibility which conforms with the observation of Irwig \& Rocks (3).

Most of the referents ( 25 out of 28 ) were currently exposed to silica dust, in contrast to the cases with silicosis ( 5 out of 28), most of whom had been exposed years ago. Thus one may have anticipated an even higher prevalence of persistent phlegm production in the referents than in the cases with silicosis ( 32 versus $43 \%$ ) had the persistent phlegm production been caused by the silica dust exposure rather than by the silicosis. This result, as well as the pulmonary function findings when the patients and their referents were compared, may, however, have been influenced by the study design. The exposure-matched referents may represent a reference group with a resistant constitution, whereas the cases with silicosis are likely to represent susceptible individuals. The referents may represent a "survival population" with respect to silicosis. Thus one may assume that the referents are more resistant to the fibrogenic effect of silica. Following this line of thought, one may also assume that the referents may be more resistent to other harmful inhalants, including smoking. However, this study design was originally adopted in order that the hereditary characteristics influencing the propensity to contract silicosis could be studied (6).

In conclusion the silicosis patients with simple or complicated (ie, in this case large radiographic opacities) silicosis showed a high prevalence of dyspnea and restrictive impairment of lung function, as well as a high prevalence of impaired $\mathrm{DL}_{\mathrm{CO}}$. The $\mathrm{DL}_{\mathrm{CO}}$ proved to be a rather sensitive lung function parameter in cases of advanced simple silicosis. Although 
smoking clearly modified the effect of silicosis on lung function, one-third of the nonsmoking patients with simple silicosis had an impaired $\mathrm{DL}_{\mathrm{CO}}$.

\section{Acknowledgments}

I wish to express my gratitude to A Zitting, MD, for his classification of the chest radiographs and to $O$ Korhonen, MD, and $\mathrm{H}$ Nordman, MD, for their useful discussions. I also wish to express my gratitude to $\mathrm{P}$ Mutanen, MSc, and J Ratilainen, MSc, for performing the statistical analyses and to N Billany, $\mathrm{BSc}$, for revising the language of this communication.

\section{References}

1. Berglund E, Birath G, Bjure J, Kjellmer I, Sandqvist L, Söderholm B. Spirometric studies in normal subjects: I Forced expirograms in subjects between 7 and 70 years of age. Acta Med Scand 173 (1963) 185-191.

2. International Labour Office. Guidelines for the use of ILO international classification of radiographs of pneumoconioses. Revised edition 1980. Geneva 1980. (Occupational safety and health series no 22 (rev 80)).

3. Irwig LM, Rocks P. Lung function and respiratory symptoms in silicotic and nonsilicotic gold miners. Am Rev Respir Dis 117 (1978) 429-435.

4. Jones RN. Silicosis. In: Rom WN, Renzetti AD, Lee JS, Archer VE, ed. Environmental and occupational medicine. Little, Brown and Company, Boston, MA 1983, pp 197-206.

5. Jones RN, Weill $\mathrm{H}$, Ziskind $\mathrm{M}$. Pulmonary function in sandblasters' silicosis. Bull Physio Path Respir 11
(1975) 589-595.

6. Koskinen $\mathbf{H}$, Tiilikainen A, Nordman H. Increased prevalence of HLA-Aw19 and of the phenogroup Aw19, B18 in advanced silicosis. Chest 83 (1983) $848-852$.

7. Medical Research Council. Definition and classification of chronic bronchitis for clinical and epidemiological purposes. Lancet 1 (1965) 775-779.

8. Parkes WR: Occupational lung disorders. Butterworths, London 1982, pp 134-174.

9. Prowse CM. Aspects of pulmonary function in silicosis in South African gold miners. In: Shapiro HA, ed. Pneumoconiosis: Proceedings of the International Conference Johannesburg. Oxford University Press, Cape Town 1970, pp 508-511.

10. Sallinen VP. Pienoiskuvauksella todetun silikoosin radiologinen ja kliininen kuva [Radiographic and clinical picture of silicosis confirmed by Mass Miniature Radiography]. Turku University, Turku 1983. (Academic dissertation).

11. Salorinne Y. Single-breath pulmonary diffusion capacity: Reference values and application in connective tissue diseases and in various lung diseases. Scand $\mathbf{J}$ Respir Dis Suppl 96 (1976) 1-84.

12. Sargent EN, Morgan WKC. Silicosis. In: Preger L, ed. Induced disease. Grune \& Stratton, New York, NY 1980, pp 297-315.

13. Teculescu BD, Stănescu DC. Carbon monoxide transfer factor for the lung in silicosis. Scand J Respir Dis 51 (1970) 150-159.

14. Ziskind M, Jones RN, Weill H. Silicosis. Am Rev Respir Dis 113 (1976) 643-665.

15. Zitting A, Huuskonen MS, Alanko K, Mattsson T. Radiographic and physiological findings in patients with asbestosis. Scand J Work Environ Health 4 (1978) $275-283$.

Received for publication: 14 February 1984 